\title{
Effects of antihypertensive drugs on surgical outcomes of breast reconstruction: a nationwide population-based claim study
}

\author{
Jin-Woo Park ${ }^{1}$, Hae Yeon Park ${ }^{2}$, Minsu Park ${ }^{3}$, Mi Yang ${ }^{4}$, Goo-Hyun Mun ${ }^{2}$ \\ ${ }^{1}$ Department of Plastic Surgery, Ewha Womans University Mokdong Hospital, College of Medicine, Ewha Womans University, 1071 Anyangcheon- \\ ro, Yangcheon-gu, Seoul, Korea; ${ }^{2}$ Department of Plastic Surgery, Samsung Medical Center, Sungkyunkwan University School of Medicine, 81 \\ Irwon-ro, Gangnam-gu, Seoul, Korea; ${ }^{3}$ Department of Statistics, Keimyung University, 1095 Dalgubeol-daero, Dalseo-gu, Daegu, Korea; ${ }^{4}$ Seoul \\ Mental Health Welfare Center, Dongsung 3-gil, Jongno-gu, Seoul, Korea \\ Contributions: (I) Conception and design: JW Park, GH Mun; (II) Administrative support: JW Park, HY Park, M Yang; (III) Provision of study \\ materials or patients: None; (IV) Collection and assembly of data: M Park, M Yang; (V) Data analysis and interpretation: All authors; (VI) Manuscript \\ writing: All authors; (VII) Final approval of manuscript: All authors. \\ Correspondence to: Goo-Hyun Mun, MD, PhD. Department of Plastic Surgery, Samsung Medical Center, Sungkyunkwan University School of \\ Medicine, 81 Irwon-ro, Gangnam-gu, Seoul 06351, Korea. Email: mungh@skku.edu.
}

Backgroundk Experimental studies have reported that angiotensin receptor blockers (ARBs) increase
the risk of surgical complications. However, clinical data on their effect on surgical outcomes are limited.
The aim of this study was to investigate the impact of perioperative use of ARBs on the outcomes of breast
reconstruction using population-based claim data. Methods: Data of patients who underwent direct-to-implant or abdomen-based autologous breast reconstruction after total mastectomy from April 2015 to December 2018 were obtained from the Health Insurance Review and Assessment Service database. The patients were categorized as ARB, non-ARB, control, and non-hypertension groups. The effects of ARBs on surgical complications, length of hospital stay, and complication-related medical costs were evaluated.

Results: Of the 9,036 patients who met the inclusion criteria, 5,192 underwent direct-to-implant reconstruction, and 3,844 underwent abdomen-based autologous reconstruction. The length of hospital stay was the longest and the surgical complication rate and complication-related medical cost were the highest in the ARB group after both reconstruction methods. Compared with non-treatment with antihypertensive drugs, ARB use was found to be an independent risk factor for surgical complications in direct-to-implant reconstruction [odds ratio (OR), 1.96; 95\% confidence interval (CI), 1.09-3.50; $\mathrm{P}=0.0237$ ] and complicationrelated medical cost (OR, 1.93; 95\% CI, 1.10-3.40; $\mathrm{P}=0.0221)$ in abdomen-based autologous reconstruction.

Conclusions: Perioperative ARB use was associated with adverse postoperative breast reconstruction outcomes. These findings might have a significant impact on perioperative antihypertensive management; nevertheless, further studies are warranted to confirm the study findings.

Keywords: Hypertension; antihypertensive drug; angiotensin receptor blocker (ARB); surgical complication; breast reconstruction

Submitted Apr 05, 2021. Accepted for publication Jun 09, 2021.

doi: $10.21037 /$ gs-21-220

View this article at: https://dx.doi.org/10.21037/gs-21-220

\section{Introduction}

Breast cancer is the most common cancer diagnosed among women, with 2.1 million new cases worldwide reported in 2018 (1). Oncologic surgery is usually the first line of treatment, and breast reconstruction has been increasingly performed $(2,3)$ based on the evidence of oncologic safety, psychological benefit, and aesthetic outcome (4-7). Breast reconstruction can be performed using either an autologous 
tissue or an implant. Among the currently used autologous reconstruction and implant-based reconstruction methods, abdomen-based autologous reconstruction and direct-toimplant (DTI) reconstruction are the most commonly used breast reconstruction methods, respectively $(8,9)$.

According to the most recent guidelines regarding the management of hypertension and cardiovascular disease, including the 2014 American College of Cardiology/ American Heart Association (ACC/AHA) guideline, 2014 European Society of Cardiology/European Society of Anaesthesiology (ESC/ESA) guidelines, and 2017 Canadian Cardiovascular Society guidelines, antihypertensive medication should be continued in the perioperative period for patients with hypertension undergoing non-cardiac surgery (10-12). This recommendation was based on the evidence that continuation of antihypertensive medication does not increase the risk of adverse postoperative cardiovascular events and mortality. However, the potential adverse effects of antihypertensive medication on surgical complications, such as wound dehiscence, hematoma, and surgical site infection, were not considered in these guidelines because there is a lack of clinical evidence on such effects.

Among various classes of antihypertensive medications, angiotensin receptor blockers (ARBs) have been reported to decrease skin flap survival $(13,14)$ and deteriorate wound healing $(15,16)$ in experimental studies. A previous retrospective study evaluating the effect of antihypertensive drugs on surgical complications after breast reconstruction in a single-center cohort has reported that $\mathrm{ARB}$ use was significantly associated with an increased risk of overall surgical complications in tissue expander reconstruction and perfusion-related complications in abdomen-based autologous reconstruction (17). The potential adverse effects of ARB use on surgical outcomes may have a clinical significance considering the high prevalence of hypertension and the fact that $\mathrm{ARBs}$ are currently one of the most widely prescribed antihypertensive medications $(18,19)$. Hence, this study aimed to evaluate the effect of $\mathrm{ARB}$ use on surgical outcomes in patients undergoing breast reconstruction using population-based claims data.

We present the following article in accordance with the STROBE reporting checklist (available at https://dx.doi. org/10.21037/gs-21-220).

\section{Methods}

This study was conducted in accordance with the Declaration of Helsinki (as revised in 2013). This study was approved by the institutional review board of Samsung Medical Center (IRB No. SMC 2019-05-015) and informed consent was waived because the research involved no more than minimal risk to the study participants due to the retrospective nature of the study.

\section{Study population}

Patients who underwent breast reconstruction after total mastectomy between April 1, 2015 and December 31, 2018 were identified from the Health Insurance Review and Assessment Service (HIRA) database using medical fee codes. Among these patients, those who underwent DTI or abdomen-based autologous breast reconstruction after total mastectomy of the unilateral breast for breast cancer [C50 or D05 according to the International Classification of Diseases (ICD)-10 codes] and who were followed up for a minimum of 3 months postoperatively were included. Bilateral and contralateral risk-reducing mastectomy cases were excluded to reduce heterogeneity of the study population. Abdomen-based autologous breast reconstruction included the use of pedicled transverse rectus abdominis myocutaneous flap, free transverse rectus abdominis myocutaneous flap, muscle-sparing free transverse rectus abdominis myocutaneous flap, and deep inferior epigastric artery perforator flap.

To evaluate the antihypertensive medication status, we determined the prescription duration of each class of antihypertensive medication within 1 year before surgery. The medication possession ratio (MPR) of the antihypertensive drugs was defined as the sum of the antihypertensive medication prescription duration divided by the follow-up duration (20). The patients were divided into four groups according to the diagnosis of hypertension and MPR of the antihypertensive medications as follows: $\mathrm{ARB}$, non-ARB, control, and non-hypertension groups. The ARB and non-ARB group included patients who were diagnosed with hypertension and treated with antihypertensive medication with or without ARBs, respectively. In particular, the ARB group included patients who were diagnosed with hypertension (I10-I15 according to the ICD-10 codes), had an MPR of $\geq 60 \%$, and were prescribed ARBs. The non-ARB group included patients who were diagnosed with hypertension, had an MPR of $\geq 60 \%$, and were not prescribed ARBs. Conversely, the control group included patients diagnosed with hypertension who were not treated with antihypertensive medication and who had an MPR of $<20 \%$. Patients who 


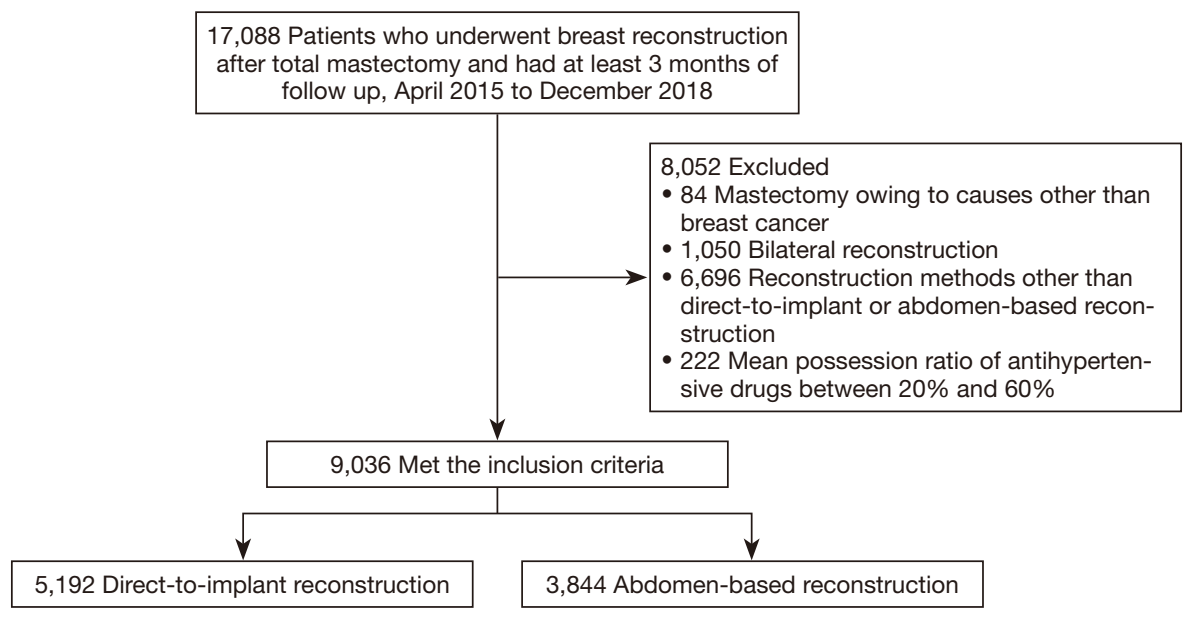

Figure 1 Flowchart of patient selection from the Health Insurance Review and Assessment Service database.

had an MPR between $20 \%$ and $60 \%$ were excluded. The non-hypertension group included patients who were not diagnosed with hypertension. The final cohort consisted of 9,036 patients, including 5,192 patients who underwent DTI reconstruction and 3,844 patients who underwent abdomen-based autologous reconstruction (Figure 1). Male patients were not identified in the study population.

\section{Variables}

The following patient characteristics were assessed: age, presence of diabetes, history of radiotherapy, history of chemotherapy, Charlson comorbidity index (CCI), and insurance status. A modified CCI was calculated as the sum of the overall extent of comorbidities for each patient using ICD-10 diagnosis codes (21).

\section{Outcome measures}

The patients were divided according to the type of reconstruction method used. The outcomes of interest were length of hospital stay, surgical complications, and complication-related medical cost. Data on surgical complications were collected using Korean Standard Classification of Diseases (KCD)-7 diagnosis codes for each surgical complication and medical fee codes for revision operation, which were claimed within 60 days postoperatively. The KCD-7 codes for infection, hematoma, wound complication, and miscellaneous or unspecified surgical complication and medical fee codes for incision, incision and drainage, wound closure, skin graft, and flap operation are included. Complication-related medical cost was calculated from the claims for inpatient prescriptions of medication, laboratory tests, imaging studies, and treatments from the day after discharge to 90 days postoperatively. Only claims from the surgery department or plastic surgery department where the breast reconstruction was performed were included; claims for postoperative radiotherapy and chemotherapy were excluded while calculating the complication-related medical cost.

\section{Data source}

As a compulsory insurance system, the Korean National Health Insurance covers approximately $97 \%$ of the entire 50 million population in South Korea, except for those supported by the National Medical Aid program $(22,23)$. The HIRA is a government-affiliated organization that performs claims review for reimbursement for medical services provided to patients (24). The HIRA database includes patient records on age, sex, diagnoses, days of hospitalization, treatments, prescriptions, and medical costs (25). Information on nearly all individuals in South Korea is available from the HIRA database because both claims data covered by the National Health Insurance and National Medical Aid program are reviewed by the HIRA. The data used in this study were retrieved from all claims data registered between April 2014 and March 2019.

\section{Statistical analysis}

Continuous variables are presented as means and standard 
deviations or medians and interquartile ranges, while categorical variables are presented as frequencies and proportions. Clinical and operative variables were compared among groups using one-way analysis of variance or the Kruskal-Wallis test for continuous variables and the chisquare test or Fisher's exact test for categorical variables. Multivariable analyses were performed using multiple logistic regression to analyze the effect of the diagnosis of hypertension and antihypertensive medication use on the outcome variables, reported as adjusted odds ratios (ORs) with $95 \%$ confidence intervals (CIs). A two-sided $\mathrm{P}$ value of $<0.05$ was considered significant. All analyses were performed using SAS version 9.4 (SAS Institute, Cary, NC, USA).

\section{Results}

\section{DTI reconstruction}

A total of 5,192 patients who underwent DTI breast reconstruction after total mastectomy of the unilateral breast were evaluated. Among them, 511 patients were diagnosed with hypertension-346 patients were classified in the $A R B$ group, 101 patients were classified in the non-ARB group, and 64 patients were classified in the control group. The 4,681 remaining patients were included in the nonhypertension group. Table 1 shows the clinical characteristics of all four groups. Patients in the ARB group were older and had a higher incidence of diabetes than those in the control group. The ARB group had a higher proportion of patients with a high CCI $(\geq 5)$ than the control group. The incidence of previous radiotherapy and chemotherapy was lower in the ARB group than in the control group. The ARB group included a higher proportion of patients who were covered by National Health Insurance than the control group. All clinical variables were significantly different among the four groups.

Table 2 presents the comparison of outcome variables among the four groups. The length of hospital stay, surgical complication rate, and complication-related medical cost were the highest in the ARB group. The differences in the length of hospital stay $(\mathrm{P}<0.0001)$ and surgical complication rate $(\mathrm{P}<0.0001)$ among the four groups were significant, while those in the complication-related medical cost were not $(\mathrm{P}=0.077)$. Multivariable analysis showed that $\mathrm{ARB}$ use was significantly associated with an increased risk of surgical complications (OR, 1.96; 95\% CI, 1.09-3.50; $\mathrm{P}=0.0237$ ) after controlling for all clinical variables, including age, presence of diabetes, previous history of radiotherapy, previous history of chemotherapy, CCI, and insurance status (Table 3).

\section{Abdomen-based autologous reconstruction}

A total of 3844 patients who underwent abdomen-based autologous reconstruction after total mastectomy of the unilateral breast were evaluated. Among them, 453 patients were diagnosed with hypertension-290 patients were classified in the ARB group, 96 patients were classified in the non-ARB group, and 67 patients were classified in the control group. The 3,391 remaining patients were included in the non-hypertension group. Table 1 shows the clinical characteristics of all four groups. Patients in the ARB group were older and had a higher incidence of diabetes than those in the control group. The ARB group had a higher proportion of patients with a high CCI $(\geq 5)$ than the control group. The incidence of previous radiotherapy and chemotherapy was lower in the ARB group than in the control group; however, the insurance status did not differ between the two groups. All clinical variables were significantly different among the four groups.

Table 2 presents the comparison of outcome variables among the four groups. The length of hospital stay, surgical complication rate, and complication-related medical cost were the highest in the ARB group. The differences in the length of hospital stay $(\mathrm{P}=0.0135)$ and complicationrelated medical cost $(\mathrm{P}=0.0471)$ among the four groups were significant, while those in the surgical complication rate were not $(\mathrm{P}=0.1873)$. Multivariable analysis showed that $\mathrm{ARB}$ use was significantly associated with an increased risk of complication-related medical cost (OR, 1.93; 95\% CI, 1.10-3.40; $\mathrm{P}=0.0221$ ) after controlling for all clinical variables, including age, presence of diabetes, previous history of radiotherapy, previous history of chemotherapy, CCI, and insurance status (Table 3).

\section{Discussion}

This study evaluated the effect of antihypertensive medication use on outcomes of DTI breast reconstruction and abdomen-based autologous breast reconstruction using population-based claims data; we found that ARB use was significantly associated with an increased risk of the surgical complications in DTI reconstruction and complicationrelated medical cost in abdomen-based autologous reconstruction.

Angiotensin II is a peptide hormone that plays important 
Table 1 Clinical characteristics of the four study groups

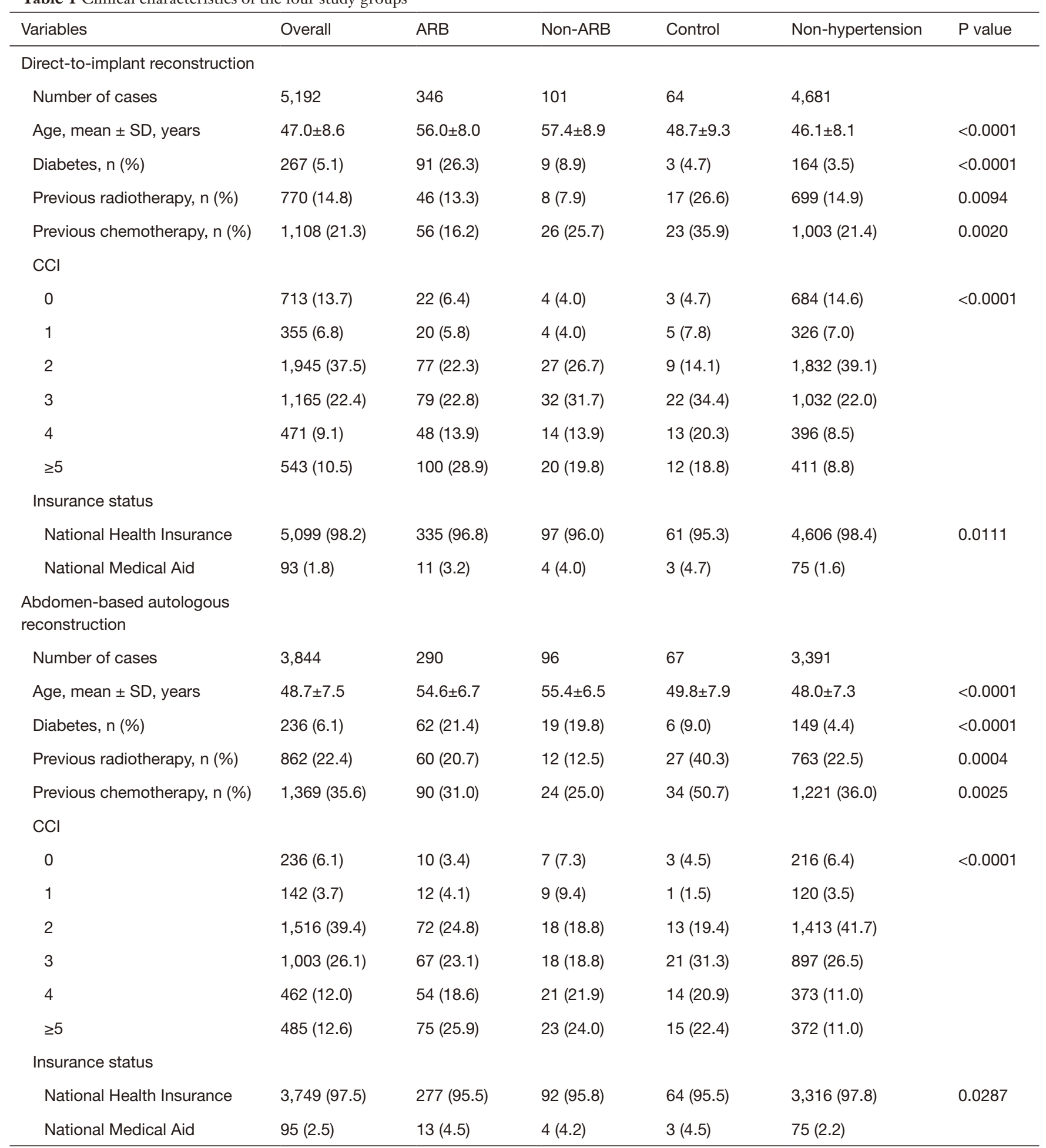

$\mathrm{ARB}$, angiotensin receptor blocker; SD, standard deviation; $\mathrm{CCl}$, Charlson comorbidity index. 
Table 2 Comparison of the outcome variables among the four study groups

\begin{tabular}{|c|c|c|c|c|c|}
\hline Outcome variables & ARB & Non-ARB & Control & Non-hypertension & $P$ value \\
\hline Length of hospital stay*, mean $\pm S D$, days & $16.0 \pm 8.7$ & $14.4 \pm 7.5$ & $14.5 \pm 10.5$ & $13.7 \pm 7.2$ & $<0.0001$ \\
\hline Surgical complication, $\mathrm{n}(\%)$ & $175(50.6)$ & $44(43.6)$ & $20(31.3)$ & $1,770(37.8)$ & $<0.0001$ \\
\hline Complication-related medical cost, median (IQR), USD & $374(81-2,054)$ & $169(66-993)$ & $237(78-941)$ & $263(84-1,411)$ & 0.077 \\
\hline Length of hospital stay*, mean $\pm S D$, days & $12.2 \pm 9.0$ & $11.5 \pm 5.9$ & $10.0 \pm 4.2$ & $11.1 \pm 5.8$ & 0.0135 \\
\hline Surgical complication, $\mathrm{n}(\%)$ & $100(34.5)$ & $25(26.0)$ & $17(25.4)$ & $987(29.1)$ & 0.1873 \\
\hline Complication-related medical cost, median (IQR), USD & 229 (82-929) & 177 (69-823) & $113(60-464)$ & 166 (77-655) & 0.0471 \\
\hline
\end{tabular}

ARB, angiotensin receptor blocker; SD, standard deviation; IQR, interquartile range; USD, United States dollar. ${ }^{*}$ Calculated as the sum of reimbursed inpatient days.

Table 3 Multivariable analyses of outcome variables

\begin{tabular}{|c|c|c|c|c|c|c|c|}
\hline Outcome variables & \multicolumn{2}{|l|}{ ARB } & \multicolumn{2}{|l|}{ Non-ARB } & \multicolumn{2}{|c|}{ Non-hypertension } & -Type 3 P value \\
\hline \multicolumn{8}{|l|}{ Direct-to-implant reconstruction } \\
\hline Length of hospital stay* & $1.28(0.74-2.23)$ & 0.3765 & $0.85(0.45-1.61)$ & 0.6144 & $1.17(0.71-1.95)$ & 0.5365 & 0.3150 \\
\hline Surgical complication & $1.96(1.09-3.50)$ & 0.0237 & $1.54(0.79-3.01)$ & 0.2095 & $1.50(0.88-2.58)$ & 0.140 & 0.0665 \\
\hline \multicolumn{8}{|c|}{ Abdomen-based autologous reconstruction } \\
\hline Length of hospital stay* & $1.69(0.87-1.25)$ & 0.1188 & $1.60(0.76-3.38)$ & 0.2148 & $1.51(0.82-2.78)$ & 0.1880 & 0.4679 \\
\hline Surgical complication & $1.51(0.81-2.76)$ & 0.1963 & $1.01(0.49-2.10)$ & 0.9708 & $1.32(0.75-2.32)$ & 0.3336 & 0.360 \\
\hline Complication-related medical cost & $1.93(1.10-3.40)$ & 0.0221 & $1.41(0.73-2.73)$ & 0.3076 & $1.46(0.87-2.45)$ & 0.1503 & 0.068 \\
\hline
\end{tabular}

Reference-control group. ARB, angiotensin receptor blocker; OR, odds ratio; Cl, confidence interval. *Calculated as the sum of reimbursed inpatient days.

roles in blood pressure regulation and salt-water homeostasis (26). ARBs act by selectively blocking angiotensin II type 1 receptor (AT1R), and clinical evidence suggests that they have cardiovascular, cerebral, and renal protective effects (27). In contrast, several experimental studies have demonstrated that angiotensin II-AT1R signaling plays a crucial role in wound healing and angiogenesis (26), and inhibition of AT1R by ARBs can cause decreased wound healing by inhibiting re-epithelialization, dermal repair, and angiogenesis (16) and reduced wound tensile strength by inhibiting collagen synthesis and deposition $(15,28)$. In addition, treatment with ARBs has been demonstrated to cause massive graft loss after meshed split-thickness skin grafting in a porcine full-thickness burn wound model (29). Based on the findings of previous experimental studies, we previously conducted a comparative analysis of the effects of various antihypertensive drugs on perfusion of a perforator flap in a rat model and found that the skin flap survival area was different according to the type of antihypertensive drug administered; the survival was the lowest in ARBtreated rats (14). We also conducted a retrospective clinical study on the effect of antihypertensive drugs on outcomes of breast reconstruction and found that ARB use was significantly associated with an increased risk of surgical complications after breast reconstruction (17). The findings of our previous clinical study regarding the effect of ARB use on surgical complications in the clinical setting were consistent with those of previous studies using experimental models $(13-16,28,29)$, despite the discrepancy in the dose and administration period of ARBs; the dose of ARBs was 
higher in experimental models $(29,30)$, and chronic use of ARBs was predominant in human subjects (17).

Hypertension is a well-known risk factor for surgical complications in various surgeries, including breast reconstruction $(31,32)$, joint replacement surgery (33-35), debulking cytoreductive surgery for ovarian cancer (36), and radical cystectomy (37). It has been also associated with increased anastomotic leaks after intestinal operation, including ileocolic anastomosis, esophagectomy, liver transplantation, and gastrectomy (38-42). The association between hypertension and the development of surgical complications is unclear; however, decreased microvasculature and underlying atherosclerosis due to hypertension have been suggested as causes for increased surgical complications $(27,32,37,39,40,42)$. Our study results suggest that antihypertensive drugs can also cause increase the risk of surgical complications in patients with hypertension. Antihypertensive drugs do not have neutral effects on wound healing, and various classes of these drugs might affect key components in wound healing (43).

Among the various classes of antihypertensive drugs, including beta-blockers, calcium channel blockers, diuretics, angiotensin-converting enzyme inhibitors, and ARBs, ARBs had been prescribed the least in the early 2000s. However, the prescription of ARB increased the most between 2001 and 2010 , accounting for $>20 \%$ of all antihypertensive medications in the USA $(18,19)$. According to the most recent guidelines regarding perioperative antihypertensive management in patients undergoing non-cardiac surgery, $\mathrm{ARBs}$ should be continued in the perioperative period. The 2014 ACC/AHA guideline suggests that continuation of ARBs perioperatively is reasonable (10). Meanwhile, the 2014 ESC/ESA guideline and the 2017 Canadian Cardiovascular Society guideline recommend perioperative discontinuation of ARBs starting 24 hours before surgery according to the risk of intraoperative hypotension; however, these guidelines also suggest that ARBs should be resumed after surgery if the patient is hemodynamically stable $(11,12)$. However, we doubt the safety of perioperative ARB use with regard to surgical complications, which was not considered in the current guidelines, based on the results of our study and previous studies that ARB use could increase surgical complications. Clinicians should then consider cessation or replacement of ARBs with other classes of antihypertensive medication during the perioperative period based on the consideration of the type of surgery and other comorbidities in the patient. In patients undergoing breast reconstruction, the authors recommend preoperative cessation or replacement of ARBs, or preoperative consultation to cardiologists in patients who have comorbidities, because several different classes of antihypertensive medications could easily replace ARB except for some specific indications for ARB. Further studies are necessary to evaluate the validity of the cessation or replacement of ARBs and establish standardized protocols for perioperative antihypertensive management in patients prescribed ARBs.

An important implication of this study is the possibility that the results might be generalized into other surgical fields. In breast reconstruction, a large area of soft tissues is removed or elevated; thus, the overlying skin flap is put under temporary reduced perfusion, which can cause perfusion- and surgical wound-related complications. We selected breast reconstruction as our study focus to evaluate the effect of ARB use on surgical outcomes because complications could easily develop in wounds with a high burden of healing (17). It can be inferred that other surgeries that have similar characteristics as breast reconstruction in the aspect of tissue perfusion can yield similar results. Surgeries that combine massive undermining of soft tissues or cause circulatory compromise at the incisional margin or anastomosis site could be good candidates for further research to evaluate the impact of $\mathrm{ARB}$ use on surgical outcomes.

This study has several limitations. First, some clinical and surgical variables that could affect surgical complications were not evaluated in this study, including body mass index, smoking history, type of mastectomy, and mastectomy specimen weight, because the nationwide claims database does not include such data. Instead, CCI, which has been demonstrated as a predictor for surgical outcomes, was used in the multivariable analysis to adjust confounding variables in this study (44-46). Second, some patients who were prescribed ARBs but did not take ARBs could have been classified into the ARB group because the study groups were divided according to medication prescription duration and not according to medication use. Therefore, the effect of ARB use on surgical outcomes could have been underestimated. Third, several reconstruction methods using abdominal flaps were combined into a single abdomen-based autologous reconstruction owing to the small sample size of each subgroup. Lastly, the HIRA database was not designed for research purposes; it has been designed for reimbursement for claims. There could also be discrepancies between the disease or treatment codes and the actual development of complications. 


\section{Conclusions}

Our study findings suggest that perioperative use of ARBs as antihypertensive medication might be associated with adverse postoperative breast reconstruction outcomes. Considering that the current guidelines regarding perioperative antihypertensive management do not reflect the potential effect of ARB use on surgical complications, further clinical studies are warranted to confirm the association between perioperative administration of ARBs and surgical outcomes.

\section{Acknowledgments}

Funding: None.

\section{Footnote}

Reporting Checklist: The authors have completed the STROBE reporting checklist. Available at https://dx.doi. org/10.21037/gs-21-220

Data Sharing Statement: Available at https://dx.doi. org/10.21037/gs-21-220

Peer Review File: Available at https://dx.doi.org/10.21037/ gs-21-220

Conflicts of Interest: All authors have completed the ICMJE uniform disclosure form (available at https://dx.doi. org/10.21037/gs-21-220). The authors have no conflicts of interest to declare.

Ethical Statement: The authors are accountable for all aspects of the work in ensuring that questions related to the accuracy or integrity of any part of the work are appropriately investigated and resolved. The study was conducted in accordance with the Declaration of Helsinki (as revised in 2013) and approved by the Institutional Review Board of Samsung Medical Center (IRB No. SMC 201905-015). Individual consent for this retrospective analysis was waived.

Open Access Statement: This is an Open Access article distributed in accordance with the Creative Commons Attribution-NonCommercial-NoDerivs 4.0 International License (CC BY-NC-ND 4.0), which permits the noncommercial replication and distribution of the article with the strict proviso that no changes or edits are made and the original work is properly cited (including links to both the formal publication through the relevant DOI and the license). See: https://creativecommons.org/licenses/by-nc-nd/4.0/.

\section{References}

1. Bray F, Ferlay J, Soerjomataram I, et al. Global cancer statistics 2018: GLOBOCAN estimates of incidence and mortality worldwide for 36 cancers in 185 countries. CA Cancer J Clin 2018;68:394-424.

2. Jagsi R, Jiang J, Momoh AO, et al. Trends and variation in use of breast reconstruction in patients with breast cancer undergoing mastectomy in the United States. J Clin Oncol 2014;32:919-26.

3. Ng YY, Tan VK, Goh TL, et al. Trends in PostMastectomy Reconstruction in an Asian Population: A 12Year Institutional Review. Breast J 2017;23:59-66.

4. Gerber B, Krause A, Dieterich M, et al. The oncological safety of skin sparing mastectomy with conservation of the nipple-areola complex and autologous reconstruction: an extended follow-up study. Ann Surg 2009;249:461-8.

5. Wu ZY, Kim HJ, Lee JW, et al. Breast Cancer Recurrence in the Nipple-Areola Complex After Nipple-Sparing Mastectomy With Immediate Breast Reconstruction for Invasive Breast Cancer. JAMA Surg 2019;154:1030-7.

6. Chen $\mathrm{W}, \mathrm{Lv} \mathrm{X}, \mathrm{Xu} \mathrm{X}$, et al. Meta-analysis for psychological impact of breast reconstruction in patients with breast cancer. Breast Cancer 2018;25:464-9.

7. Park BY, Hong SE, Hong MK, et al. The influence of contralateral breast augmentation on the development of complications in direct-to-implant breast reconstruction. J Plast Reconstr Aesthet Surg 2020;73:1268-76.

8. Song WJ, Kang SG, Kim EK, et al. Current status of and trends in post-mastectomy breast reconstruction in Korea. Arch Plast Surg 2020;47:118-25.

9. (ASPS) ASoPS. 2019 Plastic Surgery Statistics Report [Internet]. Available online: https://www.plasticsurgery. org/documents/News/Statistics/2019/plastic-surgerystatistics-full-report-2019.pdf. Accessed October 6, 2020.

10. Fleisher LA, Fleischmann KE, Auerbach AD, et al. 2014 ACC/AHA guideline on perioperative cardiovascular evaluation and management of patients undergoing noncardiac surgery: a report of the American College of Cardiology/American Heart Association Task Force on practice guidelines. J Am Coll Cardiol 2014;64:e77-137.

11. Kristensen SD, Knuuti J, Saraste A, et al. 2014 ESC/ ESA Guidelines on non-cardiac surgery: cardiovascular 
assessment and management: The Joint Task Force on non-cardiac surgery: cardiovascular assessment and management of the European Society of Cardiology (ESC) and the European Society of Anaesthesiology (ESA). Eur Heart J 2014;35:2383-431.

12. Duceppe E, Parlow J, MacDonald P, et al. Canadian Cardiovascular Society Guidelines on Perioperative Cardiac Risk Assessment and Management for Patients Who Undergo Noncardiac Surgery. Can J Cardiol 2017;33:17-32.

13. Pazoki-Toroudi H, Ajami M, Habibey R, et al. The effect of enalapril on skin flap viability is independent of angiotensin II AT1 receptors. Ann Plast Surg 2009;62:699702.

14. Park JW, Mun GH. Comparative analysis of the effect of antihypertensive drugs on the survival of perforator flaps in a rat model. Microsurgery 2018;38:310-7.

15. Criss CN, Gao Y, De Silva G, et al. The effects of Losartan on abdominal wall fascial healing. Hernia 2015;19:645-50.

16. Takeda H, Katagata Y, Hozumi Y, et al. Effects of angiotensin II receptor signaling during skin wound healing. Am J Pathol 2004;165:1653-62.

17. Park JW, Lee KT, Jeon BJ, et al. Effects of Antihypertensive Drugs on Outcomes of Breast Reconstruction. Ann Surg Oncol 2019;26:1712-9.

18. Gu Q, Burt VL, Dillon CF, et al. Trends in antihypertensive medication use and blood pressure control among United States adults with hypertension: the National Health And Nutrition Examination Survey, 2001 to 2010. Circulation 2012;126:2105-14.

19. Shah SJ, Stafford RS. Current Trends of Hypertension Treatment in the United States. Am J Hypertens 2017;30:1008-14.

20. Choi HJ, Park C, Lee YK, et al. Risk of fractures in subjects with antihypertensive medications: A nationwide claim study. Int J Cardiol 2015;184:62-7.

21. Quan H, Sundararajan V, Halfon P, et al. Coding algorithms for defining comorbidities in ICD-9-CM and ICD-10 administrative data. Med Care 2005;43:1130-9.

22. Kim S, Ahn H, Shin SA, et al. Trends of thromboprophylaxis and complications after major lower limb orthopaedic surgeries in Korea: National Health Insurance Claim Data. Thromb Res 2017;155:48-52.

23. Lee S, Hwang JI, Kim Y, et al. Venous Thromboembolism Following Hip and Knee Replacement Arthroplasty in Korea: A Nationwide Study Based on Claims Registry. J Korean Med Sci 2016;31:80-8.

24. Hwang JH, Kim BW, Jeong H, et al. Comparison of urologic complications between laparoscopic radical hysterectomy and abdominal radical hysterectomy: A nationwide study from the National Health Insurance. Gynecol Oncol 2020;158:117-22.

25. Kim L, Kim JA, Kim S. A guide for the utilization of Health Insurance Review and Assessment Service National Patient Samples. Epidemiol Health 2014;36:e2014008.

26. Kurosaka M, Suzuki T, Hosono K, et al. Reduced angiogenesis and delay in wound healing in angiotensin II type 1a receptor-deficient mice. Biomed Pharmacother 2009;63:627-34.

27. Schmieder RE. Mechanisms for the clinical benefits of angiotensin II receptor blockers. Am J Hypertens 2005;18:720-30.

28. Biondo-Simões Mde L, Zazula AD, Gomes AB, et al. Influence of arterial hypertension treated with losartan on skin healing in rats. Acta Cir Bras 2006;21:144-50.

29. Akershoek JJ, Brouwer KM, Vlig M, et al. Differential effects of Losartan and Atorvastatin in partial and full thickness burn wounds. PLoS One 2017;12:e0179350.

30. Murphy A, LeVatte T, Boudreau C, et al. Angiotensin II Type I Receptor Blockade Is Associated with Decreased Cutaneous Scar Formation in a Rat Model. Plast Reconstr Surg 2019;144:803e-13e.

31. Fischer JP, Nelson JA, Serletti JM, et al. Peri-operative risk factors associated with early tissue expander (TE) loss following immediate breast reconstruction (IBR): a review of 9305 patients from the 2005-2010 ACS-NSQIP datasets. J Plast Reconstr Aesthet Surg 2013;66:1504-12.

32. Gill PS, Hunt JP, Guerra AB, et al. A 10-year retrospective review of 758 DIEP flaps for breast reconstruction. Plast Reconstr Surg 2004;113:1153-60.

33. Bovonratwet P, Shen TS, Ast MP, et al. Reasons and Risk Factors for 30-Day Readmission After Outpatient Total Knee Arthroplasty: A Review of 3015 Cases. J Arthroplasty 2020;35:2451-7.

34. Rhee C, Lethbridge L, Richardson G, et al. Risk factors for infection, revision, death, blood transfusion and longer hospital stay 3 months and 1 year after primary total hip or knee arthroplasty. Can J Surg 2018;61:165-76.

35. Almustafa MA, Ewen AM, Deakin AH, et al. Risk Factors for Surgical Site Infection Following Lower Limb Arthroplasty: A Retrospective Cohort Analysis of 3932 Lower Limb Arthroplasty Procedures in a High Volume Arthroplasty Unit. J Arthroplasty 2018;33:1861-7.

36. Castro BGR, Dos Reis R, Cintra GF, et al. Predictive Factors for Surgical Morbidities and Adjuvant Chemotherapy Delay for Advanced Ovarian Cancer 
Patients Treated by Primary Debulking Surgery or Interval Debulking Surgery. Int J Gynecol Cancer 2018;28:1520-8.

37. Reese SW, Ji E, Paciotti M, et al. Risk factors and reasons for reoperation after radical cystectomy. Urol Oncol 2020;38:269-77.

38. Sánchez-Guillén L, Frasson M, Garcia-Granero A, et al. Risk factors for leak, complications and mortality after ileocolic anastomosis: comparison of two anastomotic techniques. Ann R Coll Surg Engl 2019;101:571-8.

39. Kassis ES, Kosinski AS, Ross P Jr, et al. Predictors of anastomotic leak after esophagectomy: an analysis of the society of thoracic surgeons general thoracic database. Ann Thorac Surg 2013;96:1919-26.

40. Kaldas FM, Korayem IM, Russell TA, et al. Assessment of Anastomotic Biliary Complications in Adult Patients Undergoing High-Acuity Liver Transplant. JAMA Surg 2019;154:431-9.

41. Alizadeh RF, Li S, Inaba C, et al. Risk Factors for Gastrointestinal Leak after Bariatric Surgery: MBASQIP

Cite this article as: Park JW, Park HY, Park M, Yang M, Mun GH. Effects of antihypertensive drugs on surgical outcomes of breast reconstruction: a nationwide populationbased claim study. Gland Surg 2021;10(7):2130-2139. doi: 10.21037/ gs-21-220
Analysis. J Am Coll Surg 2018;227:135-41.

42. Benedix F, Poranzke O, Adolf D, et al. Staple Line Leak After Primary Sleeve Gastrectomy-Risk Factors and Midterm Results: Do Patients Still Benefit from the Weight Loss Procedure? Obes Surg 2017;27:1780-8.

43. Stuermer EK, Besser M, Terberger N, et al. Side Effects of Frequently Used Antihypertensive Drugs on Wound Healing in vitro. Skin Pharmacol Physiol 2019;32:162-72.

44. Papaleontiou M, Hughes DT, Guo C, et al. PopulationBased Assessment of Complications Following Surgery for Thyroid Cancer. J Clin Endocrinol Metab 2017;102:2543-51.

45. Arrigo RT, Kalanithi P, Cheng I, et al. Charlson score is a robust predictor of 30-day complications following spinal metastasis surgery. Spine (Phila $\mathrm{Pa} 1976$ ) 2011;36:E1274-80.

46. Soohoo NF, Farng E, Lieberman JR, et al. Factors that predict short-term complication rates after total hip arthroplasty. Clin Orthop Relat Res 2010;468:2363-71. 